\title{
'Mary e Max: Uma amizade diferente': Enfocando conceitos do campo das Habilidades Sociais.
}

\section{Lucas Cordeiro Freitas*}

Universidade Federal de São Carlos - UFSCar, São Carlos, SP

MARY e Max: Uma amizade diferente. Direção e roteiro: Adam Elliot. Produção: Mark Gooder, Paul Hardart, Tom Hardart, Bryce Menzies, J onathan Page. Austrália: Gaumont, 2009. 92 min.

Uma relação de amizade pouco provável entre uma menina de oito anos que vive na Austrália e um homem de 44 na América do Norte é o fio condutor da animação stop-motion australiana Mary e Max: Uma amizade diferente, lançada em 2009. Nesse cenário ficcional, o contato entre os dois personagens se dá exclusivamente por meio de cartas, em uma época em que a comunicação virtual era uma possibilidade relativamente distante.

A relação entre Mary e Max se inicia e se mantém sustentada no isolamento social comum aos dois, que relatam reciprocamente a falta de amigos e a dificuldade em encontrá-los. Mostrado como o resultado de um longo processo na história de vida dos personagens, o filme detalha minuciosamente os fatores que contribuíram para tal isolamento, incluindo características pessoais, familiares e ambientais de forma geral.

Na biografia de Mary, é possível notar que alguns fatores ambientais, já descritos na literatura psicológica, estão intimamente relacionados ao padrão de comportamentos exibido por ela, caracterizado em grande parte por problemas de comportamento do tipo internalizante (ACHENBACH, 1991). Os comportamentos internalizantes de Mary, indicativos de isolamento, depressão e ansiedade social, aparecem relacionados a contingências aversivas tais como rejeição por pares, vitimização por bullying, violência física, convivência com familiares com transtornos mentais e práticas educativas parentais de punição inconsistente, disciplina relaxada e negligência.

Todo esse conjunto de variáveis, atuando concomitantemente, pode ser considerado fator de risco para o desenvolvimento social e acadêmico infantil, com efeitos negativos a curto e longo prazos (DEL PRETTE; DEL PRETTE, 2005; GOMIDE, 2003; MAIA; WILLIAMS, 2005; RUBIN; COPLAN; BOWKER, 2009; SALVO; SILVARES; TONI, 2005). Associados aos problemas de comportamento internalizantes, nota-se ainda o repertório restrito de habilidades sociais de Mary, que envolve desde dificuldades na expressividade facial e de sentimentos 
até o comprometimento em habilidades consideradas mais complexas como as de comunicação e de assertividade.

A história pessoal de Max é em certo ponto semelhante à de Mary no que se refere a fatores ambientais negativos, porém com uma diferença fundamental, que somente depois de já ter iniciado o contato com Mary veio a ser identificada claramente: a convivência com a Síndrome de Asperger. Max apresentava padrões comportamentais característicos de autismo, com prejuízos significativos nas interações sociais, padrão de comportamentos estereotipados e repetitivos, porém sem comprometimentos nas áreas de cognição e linguagem (APA, 2002). Nesse sentido, o repertório de habilidades sociais de Max era ainda mais deficitário que o de Mary, podendo até mesmo ser classificado como "mínimo". Por isso, as interações e relações sociais ao longo de sua vida foram poucas, sem a presença de um amigo íntimo ou de um relacionamento amoroso, ainda que passageiro. Max não era capaz de discriminar emoções básicas dos interlocutores ou de expressar habilidades sociais básicas de civilidade, como cumprimentar.

As dificuldades de Max decorrentes de sua síndrome aparecem no filme agravadas ou negligenciadas em função de fatores ambientais como exposição à violência física e psicológica, morte prematura dos pais, carência de tratamentos de saúde e pouco suporte social. Percebe-se que o personagem não teve muitas oportunidades de aprendizagem de comportamentos socialmente habilidosos ao longo da vida e que em algumas situações chegou mesmo a ser punido quando da tentativa de se comportar de forma socialmente aceitável. O início do contato entre Mary e Max, ignorando-se as diferenças de idade, gênero e nacionalidade, traduz o surgimento da primeira relação de amizade íntima e duradoura dos dois personagens. Ao mesmo tempo em que a troca de cartas se intensifica e que a amizade entre eles parece ter um impacto positivo em suas vidas, para Max a situação não é exatamente confortável, uma vez que sofre de ataques de ansiedade quando a relação com Mary parece ficar estreita demais e ele não sabe como se comportar. É visível a falta de alternativas comportamentais no repertório de Max para lidar com situações sociais que envolvem compreensão de sentimentos do outro e expressão de sentimentos próprios, sendo a ansiedade paralisante a única forma aprendida para enfrentar essas situações, ainda que envolva alto custo emocional.

Na narrativa do filme, o tempo vai passando para os personagens e outras mudanças vão progressivamente ocorrendo em suas vidas, incluindo o casamento de Mary, a morte de seus pais e a internação de Max em uma instituição psiquiátrica quando uma de suas crises chega a ser catastrófica. Nesse caminho, entre altos e baixos, conflitos e afastamentos, a amizade entre os dois se mantém, parecendo ressurgir com mais força a cada dificuldade superada. É 
possível perceber que o repertório de habilidades sociais dos dois vai se aprimorando ao longo do tempo, embora algumas habilidades só apareçam na relação entre eles e não necessariamente com outros interlocutores. A amizade vai se desdobrando também em maiores autoestima e autoeficácia, sugerindo um papel positivo da amizade sobre a avaliação que os personagens fazem de si mesmos.

Apesar de passarem anos se comunicando por cartas e de desejarem uma relação fisicamente mais próxima, o esperado encontro pessoal entre Mary e Max fica em suspenso na maior parte do filme. 0 espectador só presencia esse encontro ao final, quando descobre que a amizade entre os personagens ficará de certa forma registrada para sempre.

Devido à riqueza de detalhes com que descreve a biografia dos personagens principais, o filme realiza uma ilustração fidedigna de algumas variáveis que têm sido relatadas em pesquisas psicológicas como fatores de risco e de proteção ao desenvolvimento, especialmente aquelas relacionadas à aprendizagem e ampliação do repertório social. Profissionais e estudantes das áreas de Psicologia e Educação podem encontrar nessa animação, de conteúdo bastante adulto, um objeto de reflexão sobre as condições ambientais que favorecem ou prejudicam a aprendizagem de comportamentos socialmente habilidosos e seu impacto sobre as relações sociais em geral.

\section{Referências Bibliográficas}

ACHENBACH, T. M. Manual for the Child Behavior Checklist 4-18 and 1991 profile. Burlington: University of Vermont, 1991. AMERICAN PSYCHIATRIC ASSOCIATION. Manual diagnóstico e estatístico de transtornos mentais (DSM-IV-TR). São Paulo: Artmed, 2002.

DEL PRETTE, Z. A. P.; DEL PRETTE, A. Psicologia das habilidades sociais na infância: Teoria e prática. Petrópolis: Vozes, 2005.

GOMIDE, P. I. C. Estilos Parentais e comportamento anti-social. In: DEL PRETTE, A. ; DEL PRETTE, Z. A. P. (Orgs.). Habilidades sociais, desenvolvimento e aprendizagem: Questões conceituais, avaliação e intervenção. Campinas: Alínea, 2003, p. 21-60.

MAIA, J. M. D.; WILLIAMS, L. C. A. Fatores de risco e fatores de proteção ao desenvolvimento infantil: Uma revisão da área. Temas em Psicologia, Ribeirão Preto, v. 13, n. 2, p. 91-103, 2005.

SALVO, C. G.; SILVARES, E. F. M.; TONI, P. M. Práticas educativas como forma de predição de problemas de comportamento e competência social. Estudos de Psicologia, Campinas, v. 22, n. 2, p. 87-195, 2005.

RUBIN, K. H.; COPLAN, R. J.; BOWKER, J. C. Social withdrawal in childhood. Annual Review of Psychology, v. 60, p. 141-171, 2009. 


\section{Endereço para correspondência}

Lucas Cordeiro Freitas

Rua Argentina, 461, apto. 38, Bairro Nova Estância, CEP 13566-600, São CarlosSP, Brasil

Endereço eletrônico: Icordeirofreitas@yahoo.com.br

Recebido em: 17/06/2010

Reformulado em: 07/07/2010

Aceito para publicação em: 10/07/2010

Acompanhamento do processo editorial: Adriana Benevides Soares

\section{Notas}

* Graduado em Psicologia pela Universidade Federal de São João del-Rei (UFSJ); Mestre e Doutor em Educação Especial pela Universidade Federal de São Carlos UFSCar. 